\title{
Mauriac Syndrome
}

National Cancer Institute

\section{Source}

National Cancer Institute. Mauriac Syndrome. NCI Thesaurus. Code C130997.

A complication of poorly controlled type 1 diabetes mellitus in children characterized by linear growth impairment, glycogenic hepatopathy, and Cushingoid features. 